\title{
Nuevas aproximaciones teóricas a las regiones-commodity desde la ecología política
}

Beatriz Bustos-Gallardo. Universidad de Chile, Santiago, Chile.

Manuel Prieto. Universidad Católica del Norte, San Pedro de Atacama, Chile.

RESUMEN | Las transformaciones territoriales impulsadas por la apertura de la economía chilena al libre mercado hace cuarenta ańos han sido analizadas desde múltiples perspectivas. Una de ellas fue propuesta el año 2003 por Antonio Daher, al describir ciertas regiones como "regiones-commodity", refiriéndose a aquellas cuya actividad económica se concentra en la exportación de una o dos mercancías, como vía de inserción en los mercados globales. En este trabajo revisitamos este concepto y lo problematizamos desde la ecología política, a partir del análisis de cuatro dimensiones: producción, ciclos de boom y crisis, materialidad de la naturaleza comoditizada e identidad, aplicándolo a dos casos: las regiones de Antofagasta (minería del cobre) y de Los Lagos (salmonicultura). Nuestro argumento es que, para entender la transformación territorial que han vivido estas regiones, debemos primero reconocer el proyecto de neoliberalización territorial; y en segundo lugar, politizar el análisis de dicho proyecto mediante la consideración de la materialidad de la naturaleza que será comoditizada.

PALABRAS CLAVE | economía regional, reestructuracón territorial, regionalización.

ABSTRACT | The territorial transformations driven by the opening of the Chilean economy to the free market forty years ago have been analyzed from multiple perspectives. One of them was proposed in 2003 by Antonio Daher, describing certain regions as "commodity-regions", referring to those whose economic activity focuses on the export of one or two goods, as a way of insertion in global markets. In this work we revisit this concept and problematize it from the perspective of political ecology, based on four dimensions (production, boom and crisis cycles, materiality of commoditized nature, and identity) applied to two cases: Antofagasta Region (mining of the copper) and Los Lagos Region (salmon farming). Our argument is that, to understand the territorial transformation that these regions have experienced, we must first recognize the project of territorial neoliberalization; and second, politicize the analysis of the project by considering the materiality of nature that will be commoditized.

KEYWORDS | regional economy, territorial restructuring, regionalization.

Recibido el 14 de julio de 2017, aprobado el 4 de diciembre de 2017.

E-mails: B. Bustos, bibustos@uchilefau.cl| M. Prieto, mprieto@ucn.cl 


\section{Introducción: ¿Por qué estudiar las regiones-commodity hoy?}

Ya desde 1974, la dictadura militar implementó en el país diversas políticas territoriales y cambios estructurales que contemplaron -entre otros aspectos- la regionalización del territorio, regulaciones sobre recursos naturales, impulso a la inversión extranjera, privilegios al sector privado para la explotación de materias primas y fortalecimiento de la propiedad privada. Tales medidas impulsaron un crecimiento continuo de la economía, que permitió reducir la pobreza (de 38\% en 1990 a 13\% en 2013) y elevar el ingreso promedio nacional (de US\$ 5.000 en 1990 a 12.000 en $2012^{1}$ ). Este crecimiento, afectado por crisis económicas globales y contradicciones internas, llama la atención por sus ciclos de boom y crisis (Le Billon, 2008; Le Billon \& Good, 2016), respuestas y adaptaciones, así como por su relación con el ambiente, conflictos sociales y mercados globales.

Las crisis han abierto críticas en términos de desigualdad, exclusión social y daños ambientales: Chile es uno de los países con peor distribución del ingreso (25 veces de diferencia entre el primer y último decil) (Organización para la Cooperación y el Desarrollo Económicos [OCDE], 2015), mientras que informes sobre las cuentas ambientales señalan que alrededor del 3\% del ingreso económico nacional es a costa del medioambiente (Figueroa \& Calfucura, 2002). De hecho, la Comisión Económica para América Latina y el Caribe (Cepal, 2005, 2012) ha señalado que la concentración económica y la explotación de ventajas comparativas no han sido exitosas como estrategia de desarrollo, y que lo que se requiere es políticas de diversificación e industrialización con un activo rol del Estado.

Una de las críticas mencionadas se articula en el concepto de "región-commodity" explorado por Daher (2003), quien hace un análisis macroeconómico de aquellas regiones chilenas que se abrieron al mercado global. Constata al respecto la existencia de regiones "ganadoras" y regiones "perdedoras" ante la globalización y, además, la concentración de la acumulación económica y política en la Región Metropolitana. Tal tendencia sería expresión de una geografía donde las regiones productoras concentrarían los efectos ambientales y demográficos, mientras que el área metropolitana acumularía los beneficios económicos de la matriz exportadora.

En primer lugar, esta lectura considera las regiones como territorios predados, una suerte de contenedores geográfico-administrativos sin problematizar, que han sido producidos en coherencia con la matriz neoliberal que impulsó sus transformaciones. Segundo, el concepto solo se enfoca en los impactos económicos (restringidos a dos variables), pero no en las transformaciones territoriales que conlleva el modelo. Finalmente, considera las crisis como un fenómeno externo e impuesto, y no como una consecuencia del modo de producción del sistema de acumulación imperante.

Creemos que, bajo esta mirada, el concepto región-commodity, que caracteriza la neoliberalización del territorio, se torna neutro y pierde oportunidad de darle contenido político a la complejidad de los procesos de regionalización que transformaron Chile en los últimos cuarenta años. Daher solo considera la inserción 
global, pero minimiza la configuración política del territorio, en cuanto experiencia vivida por comunidades y sujetos situados en una historia y materialidad concretas. Si bien recientemente Daher examina los efectos socioterritoriales que ha tenido el superciclo de los commodities en Chile, mantiene una mirada apolítica y cuantitativa que se centra en dos indicadores: pobreza y desempleo (Daher, Moreno \& Aninat, 2017). Explica la vulnerabilidad de los territorios, pero lo hace sin complejizar las transformaciones metabólicas que la monoproducción intensiva de un commodity fuerza sobre los habitantes y las ecologías que los conforman. Así, para Daher, los efectos son solo sociales, no ambientales; por ende, no profundiza en la comprensión territorial de la comoditización de las regiones.

A partir de lo anterior es que queremos revitalizar este debate (continuado por Cademartori, 2007; García-Huidobro \& Maragaño, 2010; Rehner, 2012; Rehner, Baeza \& Barton, 2014, entro otros) y complementarlo desde la literatura de ecología política. A continuación, discutimos el proceso de regionalización chileno para explicar por qué forma parte central del proceso de neoliberalización territorial. Luego, revisamos la literatura de ecología política, para proponer un diseño conceptual que estudie regiones-commodity en el Chile de hoy. En la cuarta sección, presentamos una aplicación de la matriz propuesta a los casos de la industria minera en la Región de Antofagasta y la industria salmonera de la Región de Los Lagos. Finalizamos analizando las implicancias de la materialidad en la politización de las regiones-commodity estudiadas.

Este artículo es una contribución a la literatura en ecología política, en la medida en que eleva a una escala regional la discusión sobre producción y comoditización de la naturaleza. Se posiciona como un aporte a los debates en Chile sobre geografía económica y geografía regional, porque problematiza las ideas de crisis motivadas por fenómenos externos, y las entiende configuradas por la economía política de las regiones y las contradicciones internas de la incorporación de la naturaleza a los regímenes de acumulación nacional y global. Esta perspectiva permite comprender cómo los impactos de la industria, los procesos de boom y crisis, y las respuestas institucionales de los distintos sectores exportadores (forestal, minero, agrícola, etcétera) se ven territorializados en las regiones. Esto es, producen un territorio regional que, más que existir por sí mismo, se articula por medio de relaciones de poder.

\section{Regiones neoliberales}

Boisier (1988, 1992, 1993, 1994, 1995, 1998, 2000, 2010) es un autor clave en el estudio de la regionalización. Al revisar las políticas de descentralización y regionalización impulsadas durante la segunda mitad del siglo xx, Boisier afirma que en los años sesenta predominó un enfoque de crecimiento económico liderado por el Estado a través de políticas de industrialización. Durante los setenta, el crecimiento fue impulsado por el sector privado, a partir del retiro del Estado de la planificación territorial. En este marco, la regionalización debe entenderse dentro de un triángulo de políticas integrado por la organización territorial, la descentralización y la promoción del crecimiento económico. 
El ordenamiento territorial impulsado por la dictadura ${ }^{2}$ definió como requisitos para constituir una región, los siguientes: la existencia de recursos naturales que apoyen el desarrollo económico, una población suficiente para sostenerlo, una estructura urbana-rural capaz de proporcionar servicios básicos, y un tamańo administrativamente eficiente que considere cuestiones de seguridad nacional. Boisier (2000) sostiene que la descentralización corresponde a una necesidad del sistema económico en cuanto a fortalecer la capacidad de las regiones para integrarse a los mercados globales. Así, las regiones se entenderían más como unidades económicas que como entidades dotadas de historia, cultura y expresión política.

La dictadura asignó dos funciones a las regiones (Boisier 2006): atraer inversión extranjera y colocar productos en el mercado global. Ello requiere establecer una identidad y una imagen capaces de diferenciarlas dentro de espacios de competencia, con lo que se configura el desafío de construir esos atributos y asignárselos al territorio. En esta línea, el Estado ha articulado el territorio como una marca, un atributo de las mercancías producidas en un espacio determinado, dotándolo de diferenciación y competitividad a través de distintas instituciones. Entre ellas, ProChile, la Corporación de Fomento de la Producción (Corfo), el Instituto de Desarrollo Agropecuario (Indap) y la Subsecretaría de Desarrollo Regional (Subdere). Se ha dotado así a las regiones y a Chile de una "marca" país, continuando la lógica económica de la Comisión Nacional de la Reforma Administrativa (Conara), donde los aspectos políticos, culturales e identitarios son puestos al servicio de una economía global, de libre mercado y basada en la exportación de materias primas.

En el caso chileno, la implementación de la regionalización fue incompleta: mientras se dotó a las empresas de instrumentos que les facilitasen la comoditización del territorio, los órganos político-administrativos creados (intendencias y gobernaciones) no tuvieron la misma libertad ni atribuciones. La limitada participación ciudadana afectó la identificación cultural y política con las nuevas estructuras político-administrativas, lo que derivó en que los vínculos de las elites y los grupos económicos regionales con el gobierno central se dieran solo a partir de un proyecto de inserción económica global. La introducción en 1992 de los Consejos Regionales (Core, Ley $19175)^{3}$ y la elección directa de consejeros a partir del año 2013 no revirtieron la escasa injerencia de las autoridades regionales en las decisiones de política regional, su poca flexibilidad para adaptarse a cambios de los mercados internacionales, la falta de autonomía política para definir un proyecto territorial independiente y la inexistencia de recursos adecuados para la administración de territorios complejos.

Nuestro argumento es otro: el proyecto de neoliberalización requirió la comoditización del territorio. Es decir, los límites regionales político-administrativos creados en 1976 forman parte del proceso de neoliberalización territorial de las regiones. La institucionalidad y atribuciones dadas a las regiones como entidades

2 Decreto Ley 573, Estatuto del Gobierno y Administración Interiores del Estado. Ministerio del Interior, Chile, 12 de julio de 1974 [http://bcn.cl/1vbf5]; y Decreto Ley 575, Regionalización del País. Ministerio del Interior, Chile, 13 julio 1974 [http://bcn.cl/1vjwk].

3 Ley 19175, Ley Orgánica Constitucional sobre Gobierno y Administración Regional. Ministerio del Interior, Chile, 11 noviembre 1992 [http://bcn.cl/1v698]. 
político-administrativas fueron parte de un proceso estatal de disciplinamiento del territorio.

Por neoliberalización del territorio entendemos el proceso estatal de articulación de una relación de control y dominación territorial mediante instrumentos propios de un gobierno neoliberal: fortalecimiento de la propiedad privada sobre los recursos naturales, privatización de los bienes comunes, distribución y valorización de recursos vía mercado y mecanismos de gobernanza descentralizados. En Chile, este proceso creó nuevas contradicciones en la relación de las comunidades con su entorno: las instituciones y estructuras que apuntaban a la descentralización se vieron enfrentadas a la concentración en el gobierno nacional de una serie de instrumentos con incidencia concreta en los territorios (como los decretos leyes 600 y $701^{4}$ ), un sistema tributario centralizado, que impide a los gobiernos regionales crear o administrar tributos a las actividades desarrolladas en su territorio, entre otros, que fueron minimizando el gobierno regional en el proceso de transformación territorial.

En este diseño, leyes sectoriales como el Código de Aguas (1981), la Ley de Pesca (1991), el Código de Minería (1983), establecieron nuevas relaciones de propiedad con los recursos, implementando una lógica de eficiencia de mercado por sobre criterios de equidad y facilitando el despojo a quienes tenían acceso a los recursos. Otro ejemplo son las leyes Indígena y de Medio Ambiente (de 1993), que si bien reconocen y abren la participación a nuevos actores, restringen el ámbito de decisión. Estos instrumentos deterritorializan la gobernanza, asumiendo el Estado un rol de coordinador de las relaciones entre privados y comunidades, a través del cual reprime todo proceso emancipatorio (Hale, 2004).

El Estado neoliberal se circunscribe a planificar y ordenar el territorio, con miras a su apropiación privada y transacción. Las tecnologías de control y disciplinamiento territorial que pone en práctica se complementan con los instrumentos que agencias como Corfo, Indap y Sernatur (Servicio Nacional de Turismo) implementan con pequeños emprendedores, para producir bienes destinados a la exportación. De esta forma se van haciendo surgir reconfiguraciones de relaciones entre propiedad, capital y trabajo en función del último boom, pero siempre manteniendo una lógica de monoproducción para la exportación.

\section{Ecología política y el estudio de regiones-commodity}

La ecología política ofrece al menos dos caminos para nuestra problemática: el de las economías extractivas y el de las redes globales de producción (GPN, sigla de Global Production Network).

Autores como Bebbington (2009, 2012), Gudynas (2010, 2012), Petras y Veltmeyer (2014), Svampa (2013) y Watts (2004) estudian tanto las implicancias del

4 Decreto Ley 600, Estatuto de la inversión extranjera. Ministerio de Economía, Fomento y Reconstrucción, Subsecretaría de Economía, Fomento y Reconstrucción, Chile, 13 de julio de 1974 [http://bcn.cl/1w815]; Decreto Ley 701, Fija régimen legal de los terrenos forestales o preferentemente aptos para la forestación, y establece normas de fomento sobre la materia. Ministerio de Agricultura, Chile, 28 de octubre de 1974 [http://bcn.cl/1uvyc]. 
extractivismo en las comunidades, como la dinámica de relaciones entre el Estado, las empresas y las comunidades. Todos reconocen el rol central que tiene la economía extractiva para el proyecto de construcción de Estado, así como sus impactos ambientales, especialmente respecto de las tensiones con otras actividades (como la agricultura o ganadería), y el despojo que sufren comunidades campesinas e indígenas.

Pese a tal consenso, es necesario abrir la definición de extractivismo a actividades cuyo uso intensivo de recursos lleve a transformaciones irreversibles de la naturaleza, independientemente de su condición de renovables o no. Concretamente, es necesario mirar con los lentes del extractivismo los modos de producción imperantes en sectores tradicionalmente considerados como renovables, como la agricultura, industria forestal o acuicultura.

La literatura sobre GPN (Coe, Dicken \& Hess, 2008) pone acento en la red que configuran los procesos de producción global, ya sea a nivel interno de una firma o entre firmas y sectores de la economía, reconociendo tanto las nociones de poder y valor como la de embeddedness 5 . Bridge (2008) propone una lectura desde la literatura de GPN para analizar economías basadas en recursos naturales, criticando su sesgo de análisis a escala nacional y una falta de sensibilidad hacia la temporalidad y la espacialidad de la red de producción. Aplicando su propuesta a la red de producción de petróleo, muestra cómo las interfaces entre naturaleza y producción (comoditización y encierro [enclosure]) son centrales para la diferenciación de estrategias de acumulación, pues, por lo general, es el Estado el que controla estos accesos.

La mirada de GPN se concentra en los impactos territoriales de dicha inserción, así como en la interrelación de las distintas escalas que constituyen la producción. La escala también es importante desde la perspectiva del "imperativo tecnológico", que lleva a las empresas a optimizar sus costos de producción, dada la alta elasticidad del precio del tipo de mercancías que elaboran; y es importante también para identificar las barreras de acceso de distintos actores. Desde el punto de vista de los "imperativos ecológicos", Bridge (2008) señala que su consideración llama a entender la capacidad de diversos ecosistemas para absorber los impactos ambientales de la producción de materias primas. Así, la materialidad del recurso importa para establecer la forma en que se comportará la red global ante cambios en condiciones de acceso, distribución o consumo.

Sintetizando estos enfoques, Neumann (2010) propone tres caminos desde los cuales la ecología política contribuye al estudio de las regiones: primero, con teorizaciones sobre la producción social del espacio y la naturaleza; segundo, con desarrollos teóricos de economía política de recursos naturales; y tercero, con trabajos que vinculan una geografía regional orientada por el materialismo histórico, con la teoría de discursos.

Es en estos tres sentidos que entendemos la aproximación teórica a las regionescommodity, ya que nos permite estudiar la producción de paisajes, las transformaciones metabólicas en los ecosistemas, los marcos de economía política y los procesos discursivos y materiales a través de los cuales se construyen identidades y conflictos. La figura 1 sintetiza las aproximaciones existentes. 
FIGURA I Aproximaciones al estudio de regiones-commodity desde la ecología política

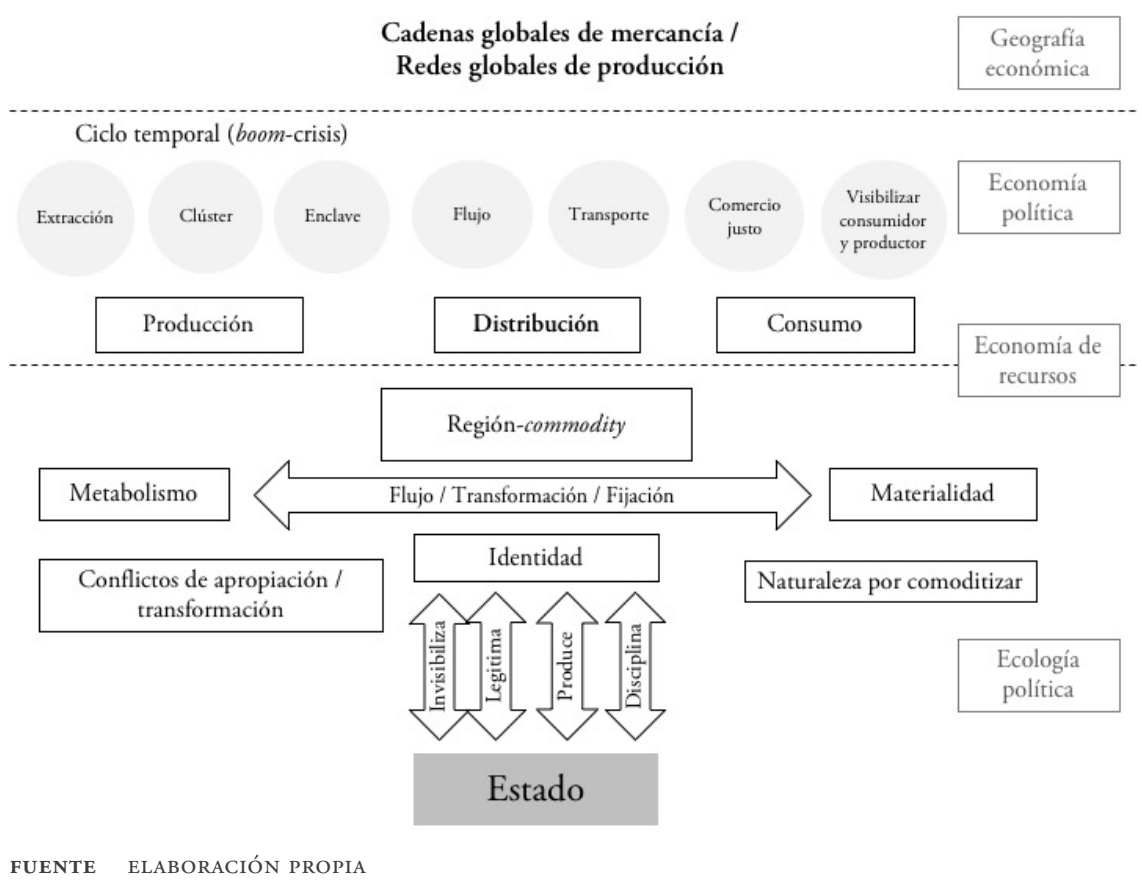

Producción social del espacio-naturaleza (la materialidad importa)

Según Castree (2003), la comoditización de la naturaleza es un proceso polimorfo a través del tiempo y el espacio, que se da en un contexto de relaciones sociales y significados fuera de la esfera económica. Así, el qué, el cómo y el dónde algo se convierte en un commodity varían y son reflejo de las relaciones sociales que se dan en contextos históricos y políticos determinados. Prudham (2009), por su parte, señala que la comoditización implica momentos de expansión y de profundización del capitalismo. Entonces, para estudiar la configuración de regiones-commodity, debemos abrir el análisis a las configuraciones histórico-sociales y de economía política que dieron pie a la primacía de la explotación de determinados recursos naturales.

Existen seis procesos en la comoditización de la naturaleza (Castree, 2003): privatización, alienación, individuación, abstracción, valoración y desplazamiento. Privatización es el establecimiento de derechos de propiedad sobre la naturaleza; alienación es la capacidad de separar el bien respecto de quien lo produce; individuación implica la diferenciación de un bien de otros análogos, en cuanto unidad transable; abstracción es la capacidad de posicionar los bienes dentro de una o más categorías comerciables; valoración supone establecer un sistema de precios que permita la valoración de un bien por mecanismos de mercado; el desplazamiento es la posibilidad de movilidad de un bien desde su lugar de producción al de consumo. 
Nevins y Peluso (2008) agregan que son los procesos de resistencia, disciplinamiento y oposición asociados a estos procesos los que configuran las diferencias entre regiones donde se generan los commodity.

\section{Economía política de recursos naturales}

La ecología política estudia los procesos de comoditización de la naturaleza, proceso que se gatilla por la introducción en la economía de distintos recursos naturales, por lo que la ecología política interroga el rol de la materialidad de dichos recursos en el ciclo productivo, en tanto obstáculo, oportunidad o sorpresa (Bakker \& Bridge, 2006; Prudham, 2005; Robertson, 2000). Boyd, Prudham y Schurman (2001) hablan de subsunción formal y subsunción real para diferenciar la forma en que el capital se relaciona con la materialidad de la naturaleza en su comoditización. La primera implica que el capital explota y extrae naturaleza para transformarla en mercancías. Ejemplos son las industrias mineras o de hidrocarburos; pero también la pesca industrial y la tala de bosque nativo. La segunda implica la transformación de las propiedades biofísicas de la naturaleza sujeta a un proceso de comoditización, con el fin de producir una nueva naturaleza que ingrese más eficientemente a los circuitos del capital. Ejemplos son las agroindustrias, las industrias forestales y las piscícolas. La industria cuprífera opera bajo una lógica de subsunción formal, ya que las vetas de cobre son removidas de la tierra, mientras que la salmonicultura requiere someter el pez a una subsunción real por medio de la alteración de su biología y la recreación de las condiciones ecosistémicas de cría.

También se hace necesario centrarse en las formas en que trabajo y capital se relacionan con la naturaleza por comoditizar, cómo se produce un determinado territorio dentro de estos procesos, cuáles son los impactos de los procesos productivos en los ciclos de vida de los ecosistemas que les dan sustento, así como las articulaciones y movilidades de los grupos humanos presentes en el territorio (por ejemplo, surgimiento de grupos, especialización productiva, movilidad de clase, migración).

Por último, los análisis metabólicos consideran los flujos de energía y de materia demandada por los procesos de comoditización, incorporándolos a la comprensión de la economía política de los recursos naturales.

Identidad y discursos que explican la materialidad en la producción de la naturaleza Entendemos que la identidad está en constante articulación y negociación (Hall, 1995). La identidad es coconstituida por procesos de transformación y resistencia en el contexto de la comoditización de la naturaleza (Prieto, 2016). Proponemos al respecto considerar tres dimensiones:

- En primer lugar, la relación entre identidad y capital, es decir, la forma en que las identidades presentes en el territorio son producidas, articuladas, disciplinadas o destruidas por la llegada del capitalismo como modo de producción; pero también, cómo dichas identidades cooperan o resisten a los procesos de acumulación implementados. Dado que las identidades son móviles y multiescalares, la mirada debe situarse a lo largo de la cadena de producción. 
- En segundo lugar, proponemos estudiar la relación entre Estado e identidades. El Estado, a través de diversos instrumentos, puede promover, producir, legitimar o disciplinar ciertas identidades, en detrimento de otras (French, 2009; Hale, 2004; Postero, 2007).

- Finalmente, creemos que es fundamental entender la relación entre identidad y la materialidad del commodity; es decir, la forma en que su condición orgánica o inorgánica genera vínculo o rechazo en el territorio, facilitando su comoditización o generando resistencia.

\section{Temporalidad de ciclos de commodity}

La existencia de ciclos de boom y crisis marca la forma en que los modos de producción responden tanto a cambios en las reservas como a las demandas. Le Billon y Good (2016) discuten la última crisis de los commodity, señalando que los ciclos involucrados no son simétricos, pero que los periodos de baja son más largos que los de expansión. En el caso chileno, existe un amplio cuerpo de trabajo sobre los ciclos y superciclos del cobre (Aroca \& Atienza, 2010; Cademártori, 2007), así como sobre sus impactos sociales (Daher, 2015). Sin embargo, para los commodities renovables, no hay el mismo tipo de seguimiento. En el caso de la industria salmonera, existen algunos análisis de la crisis del virus ISA $^{6}$ (Bustos, 2013; Bustos \& Irarrázaval, 2016), pero no análisis de largo plazo que permitan comprender el comportamiento e impactos de los ciclos de commodities como el salmón, la madera o el vino. La materialidad del commodity explicaría en parte esta situación: el carácter no renovable y mineral del cobre hace más explícita la necesidad de planificar a largo plazo su proceso de producción y comercialización, lo cual obedece a la existencia de un horizonte sobre el cual se debe actuar. Por su parte, el carácter renovable del salmón genera una falsa sensación de continuidad, la cual lleva a concentrarse en el corto plazo.

Desde una perspectiva de desarrollo territorial, se privilegia el estudio de los momentos de boom para entender cómo se usan los recursos del Estado y su capacidad de aprovechar la bonanza para complejizar la economía (Barma, Kaise, Minh Le \& Vinuela, 2012). Durante las crisis, en cambio, la atención suele concentrarse en sus efectos en las comunidades, o en las medidas necesarias para recuperarse o contener tales efectos. En general, la literatura sobre regiones-commodity en Chile tiende a evitar problematizar la crisis en cuanto a su constitución, desarrollo y resultados como forma de entender las dinámicas de los nuevos ciclos de acumulación.

Proponemos considerar la dimensión temporal de los ciclos: durante los momentos de boom, por ejemplo, atender a las dinámicas derivadas de la expansión (migración, crecimiento urbano descontrolado, aumento de la producción y del dinero circulante en la economía, mayor cantidad de desechos, etcétera); y en los momentos de crisis, considerar aquellas situaciones relacionadas con la contracción o estancamiento (emigración, disminución de la producción, agotamiento de recursos naturales, disminución de la circulación del dinero, etcétera). En ambos

El virus ISA (Anemia Infecciosa del Salmón) afecta al salmón atlántico, causando daño en el sistema inmune y heridas en su piel, haciéndolo incomercializable. 
casos, hacerlo teniendo presente la importancia de la materialidad de los commodity para entender los impactos que en ellos tienen los ciclos y la consiguiente vulnerabilidad de las economías regionales.

\section{Casos ilustrativos: cobre y salmón}

La diversidad de paisajes, regiones climáticas y ecosistemas es presentada como ventaja de la "marca Chile" en los mercados globales, al facilitar la contraestacionalidad de los productos y dotar a los commodities de atributos premium, como queda de manifiesto en la producción de mercancías orgánicas, A ello se suma una mano de obra calificada y de bajo costo, marcos institucionales que dan seguridad a las inversiones e infraestructura caminera y portuaria; lo que facilita también el desarrollo de industrias como las mineras. Tras ese discurso existe una diversidad de realidades territoriales que deben ser examinadas para entender por qué, por ejemplo, un fenómeno ambiental como un florecimiento algal en zona de producción salmonera, gatilla una movilización social sin precedentes; mientras que un proceso de estancamiento del ciclo productivo del cobre, si bien genera desempleo y la huelga más larga de la minería privada, no es capaz de movilizar reacciones sociales del mismo volumen. ${ }^{7}$

A continuación, presentamos evidencia preliminar de dos regiones que cristalizan las contradicciones del modelo económico chileno: Antofagasta (cobre) y Los Lagos (salmón). Ambas grafican la importancia de la materialidad del commodity en las transformaciones regionales, ya que el cobre, de naturaleza inorgánica, mineral y no renovable, ha sido considerado el eje de la economía chilena; mientras que el salmón, de naturaleza orgánica, biológica y renovable, en su periodo de expansión llegó a ser visto como una alternativa de inserción en la economía global. Dado el objetivo teórico de este artículo, se dejará para siguientes entregas un análisis más detallado de cada región. Lo que nos interesa en esta ocasión es demostrar el tipo de análisis desarrollado al considerar las dimensiones ya enunciadas.

\section{La Región de Antofagasta y el commodity cobre}

Antofagasta es una región minera por excelencia. De ella se extraen cobre, molibdeno, apatita, carbonato y cloruro de litio, nitratos, sulfato de sodio anhídrico y yodo. Su relevancia en la economía nacional es altísima: aporta el 45\% del PIB minero del país y, en promedio, entre el 25\% y el 30\% del total de las exportaciones nacionales (Gobierno Regional de Antofagasta, 2015). La explotación de cobre a gran escala se inició a principios del siglo xx, cuando capitales estadounidenses unificaron las pequeñas minas existente a la fecha. La adquisición de la actual mina Chuquicamata por parte de la familia Guggenheim en 1912 y luego por Anaconda en 1923, acompañada de otros fenómenos internacionales, generó un impulso a la industria que se ha mantenido en alza hasta la fecha (Fermandois, Bustos \& Schneuer, 2009). La región fue centro de los procesos de chilenización (1968), nacionalización (1971) y neoliberalización (1981) del cobre, que cambiaron la propiedad, pero

7 Estas son las movilizaciones que ocurrieron en mayo de 2016 en Chiloé y la huelga de trabajadores de minera Escondida de abril de 2017. 
no los modos y ritmos de producción. El Código de Minería actual (Ley 18248, de 1983) establece un régimen de concesiones de exploración y explotación que otorga a los titulares derecho de propiedad. En la Región de Antofagasta, estas concesiones prácticamente cubren la totalidad del territorio (figura 2), con un total de 176 minas de cobre (Servicio Nacional de Geología y Minería [Sernageomin], 2011), las que desde el ańo 2013 vienen superando ligeramente una producción de tres mil toneladas métricas finas por ańo, y alcanzaron al ańo 2015 un total del 53,3\% de la producción nacional (Sernageomin, 2016).

\section{FIgURA 2 Concesiones mineras en la Región de Antofagasta}
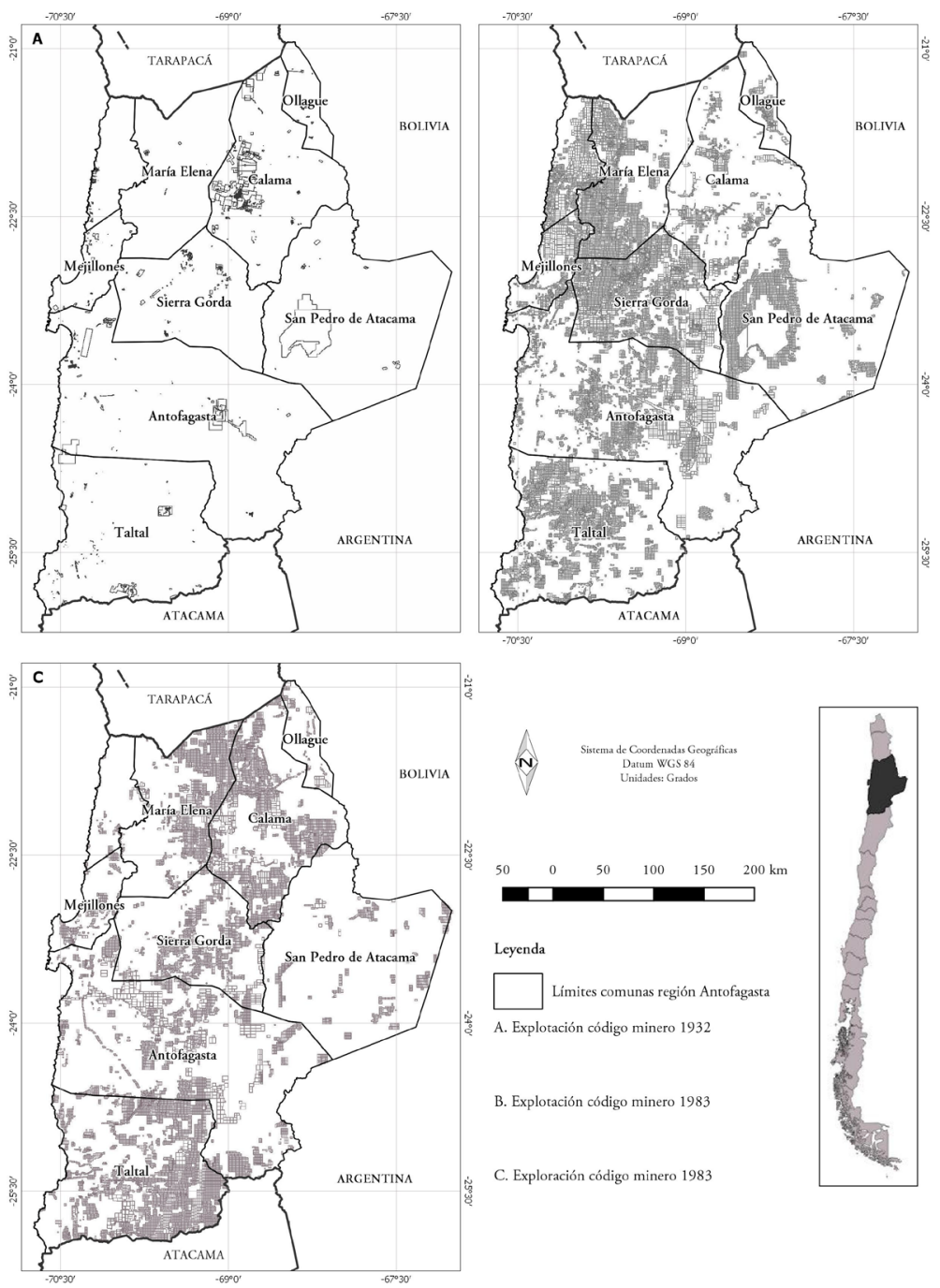

FUENTE ELABORACIÓN PROPIA CON BASE EN SERNAGEOMIN, 20 I I 


\section{Naturaleza sujeta a proceso de comodificación}

El cobre se genera por procesos de mineralización a escala geológica, que lo dejan depositado en vetas subterráneas. Esto determina la necesidad de extraerlo del subsuelo para comoditizarlo y así incorporarlo a los circuitos de mercado. No existe ninguna intervención en su materialidad que pueda acelerar los procesos de acumulación del capital minero. La misma industria ve constreñida su locación espacial por la materialidad del mineral (Bunker, 1989).

La concentración espacial de cobre a gran escala en la Región de Antofagasta implica una transformación socionatural radical, ya que obliga a la industria a remover y movilizar enormes volúmenes de tierra para obtener concentrado de mineral. Además de sus grandes reservas, la región presenta una serie de ventajas comparativas que le otorgan una vocación cuprífera: altas leyes del mineral, a pesar de la antigüedad de algunos yacimientos; geografía que facilita el manejo ambiental; acceso portuario y red de infraestructura adecuada.

\section{Metabolismo}

La explotación intensiva de minerales ha sido un factor de transformación institucional, presión ambiental, conflicto social y proletarización muy fuerte en la región desde su industrialización a principios del siglo xx. Destacan al respecto la sobreexplotación del agua, la presencia de relaves, la contaminación atmosférica, de suelos, agua, entre otros factores (Bolados, 2014; Campos-Medina, 2015; Prieto, 2017; Yáñez \& Molina, 2011). En zonas rurales, las comunidades indígenas se han visto afectadas por la minería. Algunos ejemplos son la desecación de la cuenca del río San Pedro de Inacaliri, producto de las faenas de extracción de Codelco, la Corporación Nacional del Cobre de Chile; el abandono de las terrazas de cultivo de la comunidad de Toconce, causado por la extracción de aguas por parte de la Dirección de Obras Sanitarias; la desecación de las vegas de Chiu-Chiu luego de la construcción de obras de captación para el sector minero y sanitario aguas arriba del río Loa (1980) y la privatización de los derechos de agua en 1983; la pérdida del suelo agrícola en Calama, impulsada por el auge cuprífero pos-1960, especialmente la radical expansión urbana producto de la relocalización del asentamiento minero de Chuquicamata a partir del ańo 2004 (Araya, 2006; Castro, 1997; Prieto, 2017; Yáńez \& Molina, 2011). Por otro lado, la alta demanda energética de la industria cuprífera ha radicalizado la gravedad de la contaminación atmosférica de las ciudades donde se encuentran las generadoras (principalmente combustibles fósiles), como Tocopilla (Galaz, 2017), e impulsado la instalación de nuevas generadoras, no exentas de controversia (como la central geotérmica Cerro Pabellón).

La intensificación de la extracción ha generado nuevos conflictos socioambientales, producto de la sobreexplotación de acuíferos y búsqueda de nuevas fuentes de recursos hídricos (casos de Pampa Puno, Salar de Punta Negra, Pampa Colorada), aumento de tranques de relave (Talabre), nuevos proyectos de inversión (proyecto Sulfuros Radomiro Tomic, Minera Delfín), entre otros.

Las nuevas inversiones mineras en la región han significado un aumento en las fuentes de empleo directo e indirecto en esta actividad, impulsando la inmigración, especialmente a las ciudades de Antofagasta y Calama. 


\section{Ciclo}

El comportamiento del ciclo del cobre sigue razones estructurales particulares de su proceso productivo y de las condiciones de la oferta; entre otros aspectos: i) proyecciones de consumo a largo plazo vs. déficit de proyectos; ii) disminución de la oferta por aumento de la incertidumbre debido a regulaciones ambientales y conflictos (como demandas territoriales indígenas); iii) dinamismo en la demanda internacional (altamente dependiente de la tasa de crecimiento chino); iv) innovaciones tecnológicas; v) aumento de costos de producción por envejecimiento de yacimientos. Existen otros factores coyunturales que alteran los precios del cobre a corto plazo, generando aumentos abruptos de precios; entre ellos, por ejemplo, la paralización de la producción por movimientos telúricos, climáticos o conflictos laborales.

En los últimos trece años, el ciclo de boom y crisis ha sido notorio: entre los años 2004 y 2013, el precio de las materias primas alcanzó cifras récord. Ello derivó en ingresos excepcionales para este sector y para las arcas fiscales. Durante este superciclo, el precio promedio del cobre alcanzó los us $\$ 3,43$ por libra, prácticamente el doble de los us $\$ 1,66$ promedio de los treinta ańos precedentes (1975-2004), en los que el valor excepcionalmente llegó a us\$ 2 a moneda actual (Comisión Chilena del Cobre [Cochilco], 2017). Al término del boom, los precios mínimamente superaban los us \$2. La variación del precio, desde el peak de 2011 a la caída de 2016, equivale a un devalúo de un 57\%. Esto ha repercutido fuertemente en la región, la única de Chile que presenta un aumento en el porcentaje de hogares en situación de pobreza, que ha pasado de 3,2\% en 2013 a 4,6\% en 2015 (Ministerio de Desarrollo Social, 2016).

Según Cochilco, durante la década anterior al superciclo, la industria cuprífera aportó al fisco un promedio de 5,6\% de sus ingresos anuales. Al término de este periodo, en el año 2014, los ingresos fiscales de la minería del cobre fueron de US $\$ 4.800$ millones, una cifra menor a la mitad de los us $\$ 10.400$ millones recibidos en promedio durante pleno boom.

Durante 2017, los precios del cobre subieron, en parte por vaivenes de los mercados internacionales, pero también por una baja en la oferta vinculada a la huelga laboral de Minera Escondida. A pesar de las positivas proyecciones del precio del cobre, la Región de Antofagasta no ha logrado subir las tasas de desempleo acarreadas desde el fin del superciclo, que se mantienen por sobre el promedio nacional $(7,1 \%$ respecto a un $6,2 \%$ nacional, según cifras del Instituto Nacional de Estadísticas [INE]). Estos impactos regionales también se han traducido en suspensión de proyectos inmobiliarios y caída en los permisos de construcción, disminución en la venta de supermercados y vehículos y aumento en la deuda promedio por habitantes, entre otros. Todo ello se traduce claramente en las variaciones del Índice de Actividad de la Construcción Regional (Inacor). Mientras la Región de Antofagasta lideraba dicho índice en 2013, con tasas de expansión por sobre el 10\%, a abril de 2017 la región presenta las peores tasas $(-9,1 \%)$ (Cámara Chilena de la Construcción [CCHC], 2017).

Por su parte, la baja del precio del cobre se ha visto acompañada por aumentos de precios de la energía y escasez hídrica. Ello ha llevado a la industria a rediseñar 
estrategias de gestión destinadas disminuir costos, pero manteniendo su producción (por ejemplo, inversión en energías renovables no convencionales y desalinización).

\section{Identidad}

El Estado ha sido un actor clave en la articulación de identidades vinculadas a la minería en la Región de Antofagasta, donde convergen múltiples tipos en torno a la economía política extractivista (Ministerio de Cultura, 2015). Desde tiempos históricos, su matriz de economía política ha marcado una identidad regional minera con un pasado salitrero y con constantes referencias al minero proletario. Ella ha coexistido con la presencia de comunidades indígenas, las que desarrollan actividades predominantemente agropastoriles. Luego de la guerra del Pacífico, el Estado chileno impuso una única identidad nacional mediante prácticas de chilenización, invisibilizando la identidad indígena y variables extranjeras de la región (atacameños, quechuas, bolivianos y peruanos).

Este proceso fue revertido luego, a partir de la Ley Indígena (1993), ${ }^{8}$ por políticas de reconocimiento estatales. Desde entonces se ha gatillado fuertemente la autoidentificación indígena en la región (principalmente atacameña, pero también quechua). Tal proceso no ha sido un fenómeno ajeno a la minería, sino más bien un factor clave en la articulación de una posicionalidad política frente a los conflictos ambientales, los recursos (especialmente agua) y las demandas territoriales.

Desde el auge salitrero, la región ha sido destino de migrantes que han contribuido a hibridizar la identidad regional. Durante el último tiempo, la migración boliviana y colombiana ha sido notoria, produciendo tensiones cuyas raíces se encuentran en los imaginarios racistas y nacionalistas que aún abundan en la región.

\section{La Región de Los Lagos y el commodity salmón}

Los Lagos es definida como una "Región sin Territorio, ya que las provincias que la forman (Osorno, Llanquihue, Chiloé y Palena) no comparten una noción común de territorio, ni menos una agenda regional común” (Montecinos, 2009, p. 24). Esta diversidad se manifiesta en sus actividades económicas, entre las que se cuentan los servicios, seguidos por la pesca y acuicultura y el turismo. La pesca es importante por factores tanto naturales como antrópicos: la región descansa sobre fiordos desmembrados y costas con corrientes de agua fría, además de otras condiciones idóneas para la presencia de peces. Son estas características las que han vuelto las aguas de esta región un atractivo para la salmonicultura, actividad que se consolidó como industria en los ańos setenta (Vera, 2010). A partir de entonces, y sumada a la apertura económica del país, la salmonicultura comenzó a ser el motor del crecimiento regional (Barton, 1997). Ello se ha traducido en una expansión considerable de las concesiones marinas, configurando dinámicas de exclusión sobre el maritorio (figura 3).

Los cambios regionales durante el periodo de expansión salmonera son diversos: el PIB aumentó en un 220\% entre 1996 y 2006 (INE, 2012), se observa una

Ley 19253, Establece normas sobre protección, fomento y desarrollo de los indígenas, y crea la Corporación Nacional de Desarrollo Indígena. Ministerio de Planificación y Cooperación, Chile, 5 de octubre de 1993 [http://bcn.cl/1uw3z]. 
disminución de la pobreza (-10\% en el periodo 2003-2006) y bajos niveles de desempleo en la última década $(8,56 \%)$. No obstante, la principal fuente de empleo sigue siendo los servicios y la agricultura por sobre la acuicultura (Montecinos, 2009) y se observa un patrón económico-espacial diferenciado, ya que la provincia de Osorno y el norte de la región mantienen un fuerte carácter agropecuario.

Dada la demanda de recursos naturales (agua, pesca nativa, extracción de maritorio) para la producción del salmón, y el impacto e intensidad de la producción salmonera en los ecosistemas de la región, proponemos pensar la industria salmonera como un emprendimiento de índole extractiva.

\section{FIGURA 3 Mapa de concesiones salmoneras en la Región de Los Lagos}

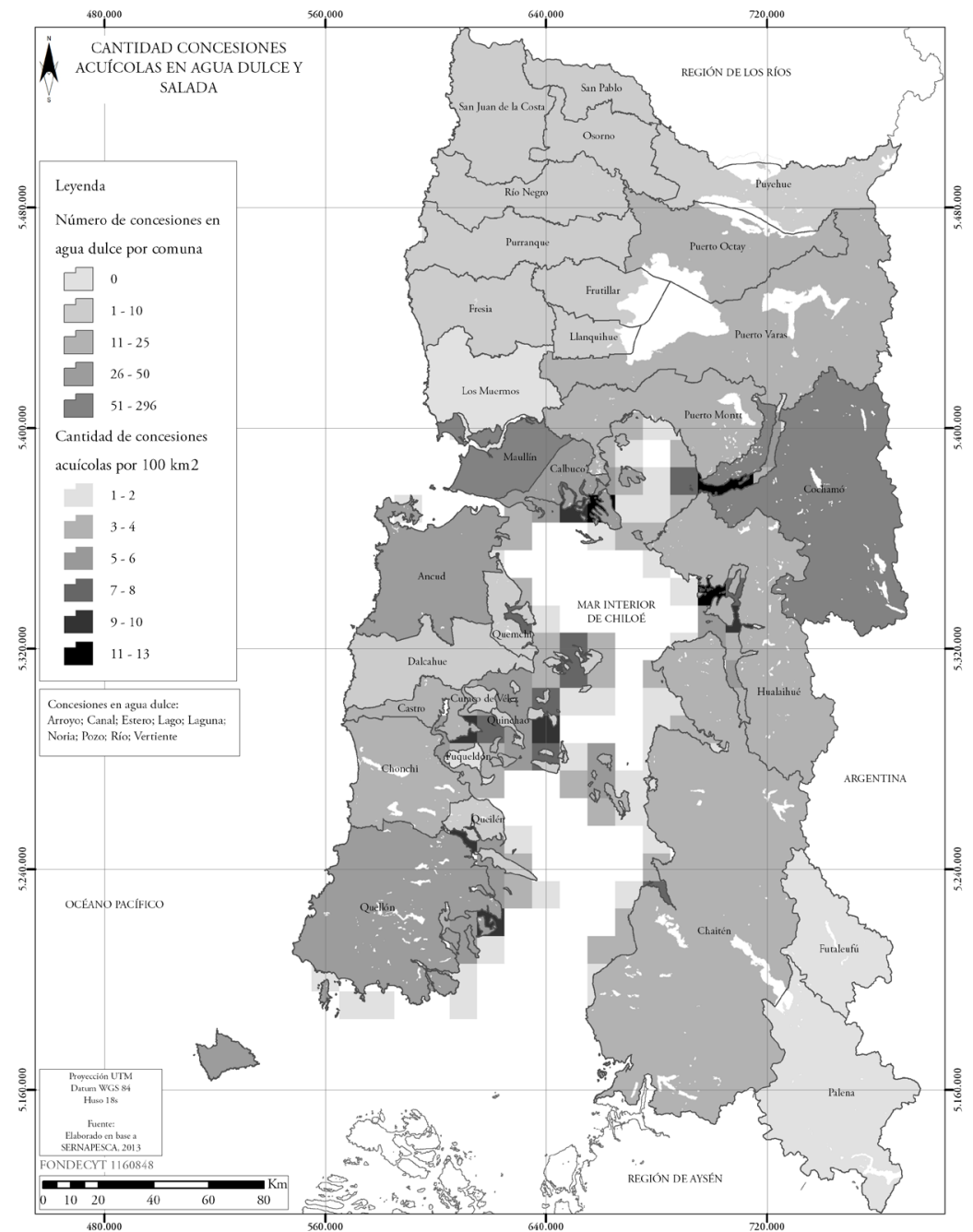

FUENTE ELABORACIÓN PROPIA CON BASE EN INFORMACIÓN DEL SERVICIO NACIONAL DE PESCA Y ACUICUlTuRA (SERNAPESCA) 


\section{Naturaleza sujeta a proceso de comodificación}

El salmón entró en la economía y ecosistema regional ya en su forma mercantilizada (como un bien privado, propiedad de las empresas) mediante marcos de derechos de propiedad (sobre aguas marinas y dulces, sobre el salmón mismo, ovas y su reproducción), innovaciones tecnológicas que permiten su supervivencia en nuevas condiciones de temperatura y luminosidad, aceleramiento de su proceso de crecimiento y maduración, y mejoramiento genético. En este sentido, la naturaleza por comodificar no es tan solo el cuerpo del salmón, sino también los cuerpos de agua (dulce y salada). Esto implicó los procesos de expulsión de usuarios previos (pescadores, recolectores de orilla, etcétera) y establecimiento de derechos de propiedad sobre las concesiones acuícolas en aguas dulces y marinas, lo que no solo transformó relaciones socioambientales, sino que también cambió ciclos hidrológicos y marinos en función de los ciclos de producción salmonera.

\section{Metabolismo}

El medioambiente ha resentido las prácticas de la salmonicultura a gran escala. Los principales rastros de la industria en las aguas de la Región de Los Lagos son fecas y comida de salmón, químicos en el agua, eutrificación y basura tanto en las costas como en el fondo marino. A esto se le suma el escape de peces, que altera la cadena trófica (León, 2006; León, Tecklin, Farías \& Díaz, 2007), lo que constituye un problema no solo para los habitantes de localidades contaminadas, sino también para la propia industria.

La comoditización del territorio regional causada por la industria salmonera ocasionó fuertes cambios en la población, tanto rural como urbana. En primer lugar, los sectores rurales recibieron pisciculturas y centros de cultivo que atrajeron a la población local y, como consecuencia, labores tradicionales como la agricultura y la pesca artesanal fueron abandonadas, principalmente por los jóvenes en busca de oportunidades (Rebolledo, 2012). Esto repercutió, además, en que la población siguiera a la industria por trabajo en sistemas de turnos y subcontrato. Los sectores urbanos, por su parte, albergan en su mayoría la fase de procesamiento, la que requiere una mayor cantidad de mano de obra, por lo que también se constituyó como un polo de trabajo. De acuerdo con información intercensal, la población regional creció 15\% entre 1982 y 2002, periodo de expansión y consolidación de la industria en la región (Montecinos, 2009), generando un rápido crecimiento urbano no planificado, con Puerto Montt como una de las ciudades de mayor crecimiento en el país en la última década (GeoCiudad Consultores, 2007).

\section{Ciclo}

El salmón, en tanto commodity biológico, tiene un ciclo corto dividido en etapas -agua dulce / alevinaje, agua de mar / engorda- y controlado por dos factores, temperatura y luz. Los tiempos en la primera etapa en piscicultura son controlados por decisiones productivas de cada empresa, pero los tiempos en la etapa de engorda están más dictados por factores ambientales. El promedio para el salmón atlántico es de catorce meses. En total, desde la fertilización hasta su cosecha, pueden ser veinticuatro meses. 
Las decisiones productivas sobre siembra y cosecha están guiadas por análisis de mercado - precio del kilo en mercados de destino, demandas de consumidores- y por factores políticos externos. Durante los últimos años el ciclo ha estado operando de manera volátil. Tras la crisis de 2008, los precios del mercado mundial subieron de manera importante, por la menor disponibilidad de peces tras la pérdida de la industria chilena. El efecto rebote llevó a que la industria chilena, necesitando mejorar sus resultados, sembrara demasiado, proceso incentivado también por la crisis de Ucrania, que cerró el salmón noruego al mercado ruso. La sobreoferta llevó a una nueva baja del precio mundial, lo que, sumado a los mayores costos de producción del salmón chileno por la nueva regulación sanitaria, ha derivado en que la industria haya estado operando a pérdida durante los últimos cinco ańos. Recién en 2016 las empresas chilenas lograron resultados financieros positivos. Previo a este periodo de inestabilidad, el ciclo llevaba varios años de expansión, que incentivaron a la industria chilena a aumentar su producción de manera exponencial, con efectos secundarios como un crecimiento urbano no planificado y la proletarización de la mano de obra; al mismo tiempo, llevaron a revertir patrones de migración, así como a la reconfiguración de prácticas económicas alternativas. El año 2006, en pleno apogeo, el entonces senador Camilo Escalona propuso la introducción de un royalty a la industria salmonera, en consideración a los costos ambientales y económicos que ella genera. Este debate da cuenta de que el cuestionamiento a la contribución real de la industria a la economía regional fue planteado previo a la crisis, cuyo efecto, entonces, fue suprimir esta discusión.

Las crisis que han marcado los ciclos de la industria salmonera responden a razones ecológicas: el virus ISA fue un momento de sobreexplotación del recurso agua y del bienestar animal. Por su parte, la crisis de 2016 fue causada por un florecimiento algal que responde a un ecosistema estresado y poco resiliente. Ambos momentos han expuesto la materialidad de la biología del salmón ante condiciones de producción intensivas, expandiendo estos factores hacia todo el ecosistema y hacia las actividades económicas alternativas que se insertan en él. Tal situación lleva a plantear la importancia de la dimensión ecológica en el ciclo de acumulación del capital (Bustos \& Irarrázaval, 2016), pero también la necesidad de mecanismos como el royalty, que retribuyan a la región. Uno de estos mecanismos fue el establecimiento, en 2014, de patentes salmoneras, que se destinan 50\% al gobierno regional y $50 \%$ al municipio donde se encuentran las concesiones operativas.

Las consecuencias sociales y territoriales de esta volatilidad han sido importantes. La crisis del virus ISA en 2007 llevó a las empresas a cerrar sus operaciones, a la disminución de salarios, la reducción de trabajadores y la precarización laboral. Por su parte, la población que migró por la industria volvió a sus localidades y a trabajar en el campo. Hoy, el sector acuícola sigue siendo relevante en la región, pero cabe preguntarse bajo qué condiciones se vinculará la industria a la región a futuro.

\section{Identidad}

La Región de los Lagos es un territorio con múltiples actores e identidades vinculadas a su geografía y economía de borde costero: la pesca artesanal, la agricultura; y ahora, más recientemente, la salmonicultura. En la base de todas ellas se encuentran 
las raíces española e indígena, fuertemente asentadas en el imaginario regional como las fuerzas motrices que diferencian a Chiloé y la región del resto del país. Estas identidades, articuladas en un territorio común y con la particularidad de la fuerte presencia de la industria salmonera, han sido forzadas a relacionarse de nuevas maneras con su propio contexto, hoy mercantilizado. Mientras algunos (indígenas y pescadores artesanales) han generado estrategias de asimilación o de resistencia ante la intervención del Estado mediante leyes que cambian las formas de acceso y uso del borde costero, otros (campesinos) han debido adaptarse a un nuevo escenario orientado a la monoproducción.

Tanto el pescador como el agricultor han enfrentado las contradicciones que implica ser parte de una cultura tradicional expuesta a mercados abiertos y políticas estatales que impulsan el protagonismo del mercado. El salmonero, en tanto, es un nuevo sujeto que llega a la Región de Los Lagos y encarna en sí mismo el imaginario social que se le atribuye a la industria salmonera: modernidad, riqueza y transformación. Se convierte así en una figura disruptiva, que fuerza a los habitantes tradicionales a asumir una estrategia, ya sea de adaptación-dadas las lógicas de uso y producción comunes tanto a la pesca como a la agricultura (cultivo, cosecha, mar, dureza) - o de resistencia, que lleva al Estado y a la industria a aplicar estrategias que faciliten tanto el disciplinamiento como el control.

Tras los procesos descritos se encuentra un conjunto de instrumentos del Estado, como la Ley de Pesca o la Ley Indígena, que establecieron los criterios de legitimación de las identidades en el territorio y los procedimientos de acceso, control y uso de los recursos en la región, pero a la vez alteraron la dinámica de relaciones entre los actores.

\section{Conclusiones}

Nuestro argumento ha sido que, para entender las regiones-commodity, se hace necesario interrogar sus territorios no como meros contenedores de dinámicas económicas y de poder, sino como entes articulados a partir de esas relaciones. En este sentido, este artículo es una invitación a politizar el análisis del proyecto de reconfiguración neoliberal del territorio. Ello por medio de un marco de ecología política que, desde la historia y economía política, considere las distintas dimensiones aquí estudiadas: naturaleza en proceso de comoditización, identidad, ciclos de producción y metabolismo.

El examen del caso de la Región de Antofagasta muestra una región fuertemente marcada por la presencia y acción estatal desde su anexión al territorio nacional, ya sea por el impulso a la actividad minera cuprífera o por la activación de dispositivos de control de movilizaciones sociales y laborales (incluidas la represión violenta de inicios del siglo xx y la entrega de bonos en las negociaciones sindicales del siglo xxI). Al mismo tiempo, la zona aparece determinada por la generación de nuevas identidades (indígenas), que se insertan en un territorio producido desde y para la minería, y donde tienen que reaccionar desde y para la continuidad de la producción cuprífera.

La revisión de lo ocurrido en la Región de Los Lagos muestra que en los últimos cuarenta años se ha visto activamente empujada por la acción estatal hacia la 
monoproducción salmonera. Ello ha ocurrido pese a que en sus territorios conviven otras actividades económicas, las cuales se han visto afectadas en materias que abarcan desde los efectos de la degradación ambiental, al surgimiento de identidades que reconfiguran el acceso y control territorial. La activa intervención del Estado en la introducción y expansión de la industria -mediante la creación de mecanismos de derechos de propiedad sobre las concesiones acuícolas, los registros de la pesca artesanal, los Espacios Costeros Marinos de Pueblos Originarios, y otra serie de subsidios destinados a la agricultura- ha introducido lógicas económicas y políticas de propiedad privada en las relaciones de las comunidades con sus territorios. Como respuesta, las comunidades han adaptado sus identidades a las dinámicas imperantes, pero también han desarrollado mecanismos de resistencia al proceso de exclusión y despojo que han vivido.

Dado que ambos commodities - cobre y salmones- están sujetos a ciclos de boom y crisis, es importante profundizar el rol de la escala en la reacción a las crisis: si se considera la importancia de la minería para la economía nacional, se tiene que sus efectos son mucho más amplios que la crisis en la industria salmonera. No obstante, pese a su efecto más contenido, fue la crisis salmonera la que llevó a un cuestionamiento nacional de la existencia de la industria salmonera, mientras que la crisis minera aún no logra gatillar ese debate.

La situación señalada puede tener relación con la materialidad del commodity: el carácter inorgánico y, por consiguiente, la imposibilidad de "producir" cobre, determina la inamovilidad de la explotación y de los efectos de esta condición. Por su parte, la larga historia de la Región de Antofagasta como región minera en relación con las grandes reservas de cobre ha determinado una aceptación de los efectos de esta industria. Ello en la medida en que se perciba una cierta retribución desde el país por parte de quienes trabajan en minería.

Por el contrario, el carácter orgánico del salmón facilita la manipulación de su biología y condiciones de reproducción, lo que hace más explícito el conflicto social vinculado a las contradicciones ecológicas que conlleva su comoditización. En consecuencia, la Región de Los Lagos se lee como un territorio en disputa, mientras que Antofagasta es más bien un territorio productivo, asumido en su rol nacional, pero insatisfecho con su participación en el desarrollo nacional.

Lo anterior lleva a dos aproximaciones políticas distintas en las relaciones Estado-comunidad, donde la identidad de las comunidades regionales en relación con el commodity respectivo desempeña una función importante en la capacidad del sistema político de legitimar modos de producción similares ante condiciones de materialidad distintas. Los efectos concretos del ciclo de boom y crisis (gatillado por variaciones en el precio) en la biología del salmón y cuerpos de agua donde se produce, generan una rápida reacción en las dinámicas políticas regionales. Por su parte, las variaciones en el precio del cobre tienen tal peso en la economía nacional, que los efectos regionales se asumen como un sacrificio necesario, por la promesa del desarrollo.

Los procesos políticos de producción de paisaje en las regiones-commodity de Antofagasta y Los Lagos tienen en común la neoliberalización de la naturaleza, que obviamente implica transformaciones metabólicas, particularmente claras en 
el recurso agua en ambas regiones. Más allá de eso, sin embargo, debe tenerse en cuenta las transformaciones institucionales inherentes a dichos procesos, visibles, por ejemplo, en la creación de derechos de propiedad privados que reconfiguran la relación de los habitantes de la región con su territorio. Es por ello que las regionescommodity se definen no solo por la producción de un bien primario predominante, sino también por la reconfiguración de paisajes, identidades, instituciones e interacciones metabólicas sociedad-naturaleza, en función de la neoliberalización de todo el territorio políticamente producido.

\section{Agradecimientos}

Artículo financiado por el Proyecto Fondecyt 1160848. Por su parte, Manuel Prieto agradece al Fondap Center for Indigenous and Intercultural Research (CIIR).

\section{Referencias bibliográficas}

Araya, L. (2006). Los derechos de uso de agua de los agricultores de Calama ¿son efectivos? Tesis para optar al grado de magíster, Pontificia Universidad Católica de Chile, Santiago, Chile.

Aroca, P. \& Atienza, M. (2010). Potencialidad económica regional. En A. Llagostera (ed.), Región de Antofagasta. Pasado, presente y futuro en el Bicentenario de Chile, 1810-2010 (pp. 403-419). Antofagasta: Universidad Católica del Norte.

Bakker, K. \& Bridge, G. (2006). Material worlds? Resource geographies and the 'matter of nature'. Progress in Human Geography, 30(1), 5-27. https://doi. org/10.1191/0309132506ph588oa

Barma, N., Kaiser, K., Minh Le, T. \& Viñuela, L. (2012). Rents to riches? The political economy of natural resource-led development. Washington, D.c.: World Bank. https:// openknowledge.worldbank.org/handle/10986/2381

Barton, J. R. (1997). ¿Revolución azul? El impacto regional de la acuicultura del salmón en Chile. EURE, 22(68), 57-76. http://www.eure.cl/index.php/eure/article/view/1156

Bebbington, A. (2009). The new extraction: Rewriting the political ecology of the Andes? NACLA Report on the Americas, 42(5), 12-20. https://doi.org/10.1080/10714839.200 9.11722221

Bebbington, A. (2012). Underground political ecologies: The second Annual Lecture of the Cultural and Political Ecology Specialty Group of the Association of American Geographers. Geoforum, 43(6), 1152-1162. https://doi.org/10.1016/j. geoforum.2012.05.011

Boisier, S. (1988). Palimpsesto de las regiones como espacios socialmente construidos. Documento 88/02 Serie Ensayos. Santiago: Instituto Latinoamericano de Planificación Económica y Social (Ilpes). https://repositorio.cepal.org/handle/11362/33600

Boisier, S. (1990). La descentralización: un tema confuso y difuso. Documento 90/05. Serie Ensayos. Santiago: Instituto Latinoamericano de Planificación Económica y Social (Ilpes). https://repositorio.cepal.org/handle/11362/8835. [Publicado en D. Nolhen (ed.), Descentralización politica y consolidación democrática: Europa-América del Sur. Caracas: Síntesis/Editorial Nueva Sociedad, 1991. 
Boisier, S. (1995). Regiones pivotales y regiones virtuales, posmodernismo territorial y globalización. Revista Foro (25), diciembre.

Boisier, S. (1998). Post-scriptum sobre desarrollo regional: Modelos reales y modelos mentales. EURE, 24(72): 53-69. http://dx.doi.org/10.4067/S0250-71611998007200003

Boisier, S. (2000). Chile: la vocación regionalista del gobierno militar. EURE, 26(77), 81-107. http://dx.doi.org/10.4067/S0250-71612000007700004

Boisier, S. (2004). Desarrollo territorial y descentralización: El desarrollo en el lugar y en las manos de la gente. EURE, 30(90), 27-40. http://dx.doi.org/10.4067/S025071612004009000003

Boisier, S. (2006). La imperiosa necesidad de ser diferente en la globalización: el mercadeo territorial. La experiencia de las regiones chilenas. Territorios, (15), 71-85. http://www. redalyc.org/pdf/357/35711624005.pdf

Boisier, S. (2009). El lenguaje emergente en desarrollo territorial. Santiago: Centro de Anacción (Análisis y Acción) Territorio y Sociedad (CATs). https://bit.ly/2v4V6Iu

Bolados, P. (2014). Los conflictos etnoambientales de "Pampa Colorada" y "El Tatio" en el Salar de Atacama, norte de Chile. Procesos étnicos en un contexto minero y turístico transnacional. Estudios Atacameños (48), 228-248. http://dx.doi.org/10.4067/S071810432014000200015

Boyd, W., Prudham, W. S. \& Schurman, R. A. (2001). Industrial dynamics and the problem of nature. Society \& Natural Resources, 14(7), 555-570. https://doi. org/10.1080/08941920120686

Bridge, G. (2008). Global production networks and the extractive sector: Governing resourcebased development. Journal of Economic Geography, 8(3), 389-419. https://doi. org/10.1093/jeg/lbn009

Bunker, S. (1989). Staples, links, and poles in the construction of regional development theories. Sociological Forum, 4(4), 589-610. http://dx.doi.org/10.1007/BF01115065

Bustos, B. (2013). The ISA crisis in Los Lagos, Chile: A failure of neoliberal environmental governance? Geoforum, 48, 196-206. https://doi.org/10.1016/j.geoforum.2013.04.025

Bustos, B. \& Irarrázaval, F. (2016). "Throwing Money into the Sea”: Capitalism as a worldecological system. evidence from the Chilean salmon industry crisis, 2008. Capitalism Nature Socialism, 27(3), 83-102. https://doi.org/10.1080/10455752.2016.1162822

Cademártori, J. J. (2007). El impacto de la inversión extranjera 1990-2000 sobre el desarrollo durable de la región minera de Antofagasta (Chile). Tesis para optar al grado de doctor en Ciencias Sociales, Université Catholique de Louvain. https://dial.uclouvain.be/pr/ boreal/object/boreal:6240

Cámara Chilena de la Constucción (CCHC) (2017). Indicadores: INCACOR [Índice de la Actividad de la Construcción Regional]. http://www.cchc.cl/centro-de-informacion/ indicadores/inacor

Campos-Medina, F. (2015). Could the search for sustainability reinforce socio-ecological conflict? The mining industry in Chile and its impact at the local and regional level. En B. Werlen (ed.), Global Sustainability (pp. 267-295). Basilea, Suiza: Springer International Publishing.

Castree, N. (2003). Commodifying what nature? Progress in Human Geography, 27(3), $273-$ 297. https://doi.org/10.1191/0309132503ph428oa 
Castro, V. (1997). Fragilidades, equilibrios y ética. Sobre patrimonios culturales y naturales. MACH (15), 23-27.

Coe, N. M., Dicken, P. \& Hess, M. (2008). Introduction: global production networksdebates and challenges. Journal of Economic Geography, 8(3), 267-269. https://doi. org $/ 10.1093 / \mathrm{jeg} / \mathrm{lbn} 006$

Comisión Chilena del Cobre (Cochilco) (2017). Precio del cobre refinado, nominal y real. https://bit.ly/2w3s7Wc

Comisión Económica para América Latina y el Caribe (Cepal) (2005). Evaluaciones del desempeño ambiental. Chile (LC/L.2305). [Publicado originalmente por la OCDE en inglés y francés, 2005]. Santiago: Naciones Unidas, Cepal. https://www.cepal.org/es/ publicaciones/1288-evaluaciones-desempeno-ambiental-chile

Comisión Económica para América Latina y el Caribe (Cepal) (2012). Población, territorio y desarrollo sostenible (LC/L.3474(CEP.2/3)). Santiago: Centro Latinoamericano y Caribeño de Demografía (Celade) - División de Población de la Cepal. https:// repositorio.cepal.org/handle/11362/22425

Consejo Nacional de la Cultura y las Artes, Chile. Departamento de Estudios (2015). Región de Antofagasta. Sintesis Regional. https://bit.ly/2LhMuaD

Daher, A. (2003). Regiones-commodities. Crisis y contagio en Chile. EURE, 29(86), 89-108. http://dx.doi.org/10.4067/S0250-71612003008600005

Daher, A. (2015). Chile y Antofagasta en las crisis internacionales En AA.vV., Sistemas, coaliciones, actores y desarrollo económico territorial en regiones mineras (pp. 141-158). Antofagasta: Universidad Católica del Norte. http://www.cemp.ucn.cl/images/LibroITA-definitiva-1.pdf

Daher, A., Moreno, D. \& Aninat, M. (2017). Efectos socioterritoriales en Chile del súper ciclo de los commodities y de su término. Cadernos Metrópole, 19(38), 127-155. http:// dx.doi.org/10.1590/2236-9996.2017-3805

Fermandois, J., Bustos, J. \& Schneuer, M. J. (2009). Historia política del cobre 1945-2008. Santiago: Centro de Estudios Bicentenario.

Figueroa, E. \& Calfucura, E. (2002). Depreciación del capital natural, ingreso y crecimiento sostenible: lecciones de la experiencia chilena. Documento de Trabajo 138. Banco Central de Chile. http://si2.bcentral.cl/public/pdf/documentos-trabajo/pdf/dtbc138.pdf

French, J. H. (2009). Legalizing identities: Becoming Black or Indian in Brazil's northeast. Chapel Hill, N.C.: University of North Carolina Press.

Galaz, D. (2017). Inclusiones, transformaciones y asimetrías del capitalismo minero en la costa de Atacama. Derivaciones de la termogeneración de energía eléctrica en Tocopilla (Chile) 1914-2015. Tesis para optar al grado de doctor en Antropología, Universidad Católica del Norte, Universidad de Tarapacá, Rennes 2 (Historia), San Pedro de Atacama.

García-Huidobro, A. \& Maragaño, A. (2010). La vertebración territorial en regiones de alta especialización: Valle Central de Chile. Alcances para el desarrollo de zonas rezagadas en torno a los recursos naturales. EURE, 36, 49-65. http://dx.doi.org/10.4067/S025071612010000100003

GeoCiudad_Consultores. (2007). Análisis de tendencias de localización 2005-2012. Etapa I, Caso: Sistema Urbano Puerto Montt - Alerce - Puerto Varas. Santiago: Ministerio de Vivienda y Urbanismo. https://bit.ly/2uvgVAL 
Gobierno Regional de Antofagasta (2015). Región de Antofagasta / Aspectos económicos. https:// bit.ly/2AtxqT6

Gudynas, E. (2010). Agropecuaria y nuevo extractivismo bajo los gobiernos progresistas de América del Sur. Territorios, 5, 37-54.

Gudynas, E. (2012). Estado compensador y nuevos extractivismos. Las ambivalencias del progresismo sudamericano. Nueva Sociedad (237), 128-146. https://bit.ly/2mZ9jTp

Guizardi, M. L. \& Garcés, A. (2013). Circuitos migrantes: Itinerarios y formación de redes migratorias entre Perú, Bolivia, Chile y Argentina en el Norte Grande chileno. Papeles de Población, 19(78), 65-110. https://bit.ly/2LmPlzd

Hale, C. (2004). Rethinking indigenous politics in the era of the "Indio Permitido". NACLA Report on the Americas, 38(2), 16-21. https://doi.org/10.1080/10714839.2004.11724509

Hall, S. (1995). Negotiating Caribbean identities. New Left Review I(209), 3-14.

Instituto Nacional de Estadísticas (INE), Chile (2012). Censo 2012. Resultados XVIII Censo de Población. Santiago: INE. https://bit.ly/2L4cozB [Síntesis de resultados en https://bit. ly/2BHrNx3].

Instituto Nacional de Estadísticas (INE), Chile (2018). Nota Estadística Informalidad Laboral Encuesta Nacional de Empleo. https://bit.ly/2v354tX

Le Billon, P. (2008). Diamond wars? Conflict diamonds and geographies of resource wars. Annals of the Association of American Geographers, 98(2), 345-372. https://doi. org/10.1080/00045600801922422

Le Billon, P. \& Good, E. (2016). Responding to the commodity bust: Downturns, policies and poverty in extractive sector dependent countries. The Extractive Industries and Society, 3(1), 204-216. https://doi.org/10.1016/j.exis.2015.12.004

León, J. (2006). Sinopsis de los impactos y la gestión ambiental en la salmonicultura chilena. Informe técnico de consultoría. En S. Díaz \& J. León (eds.), Actas Taller Cientifico: Investigación ambiental en la salmonicultura chilena: ¿Gasto o inversión? (pp. 9-46). Valdivia: www Chile. https://bit.ly/2zReE83

León, J., Tecklin, D., Farías, A. \& Díaz, S. (2007). Salmonicultura en los lagos del sur de ChileEcorregión valdiviana. Historia, tendencias e impactos medioambientales. Valdivia: WwF Chile / Núcleo Científico Milenio Forecos, Universidad Austral de Chile. https://bit. ly/2LhmfRI

Ministerio de Cultura (2015). Región de Antofagasta, Síntesis Regional. http://www.cultura. gob.cl/wp-content/uploads/2015/08/Informe-Antofagasta-final.pdf

Ministerio de Desarrollo Social, Chile (2016). Informe de Desarrollo Social 2016. https://bit. ly/2NrAEby

Montecinos, E. (2009). Informe. Articulación de actores para la descentralización. Región de Los Lagos. En G. Delamaza, N. Cunill, \& A. Joignan (eds.), Estudio Articulación de actores para la descentralización en tres regiones de Chile: Arica-Parinacota, Coquimbo y Los Lagos. Santiago: Subsecretaría de Desarrollo Regional (Subdere), Programa en Innovación en Ciudadanía.

Neumann, R. P. (2010). Political ecology II: Theorizing region. Progress in Human Geography, 34(3), 368-374. https://doi.org/10.1177/0309132509343045

Nevins, J. \& Peluso, N. L. (2008). Taking Southeast Asia to market: commodities, nature, and people in the neoliberal age. Ithaca, NY: Cornell University Press. 
Organización para la Cooperación y el Desarrollo Económicos (OCDE) (2015, 21 de mayo). ¿Por qué reducir la desigualdad nos beneficia?... en Chile. Todos Juntos. [Nota de prensa]. https://bit.ly/2uLJXeH

Petras, J. \& Veltmeyer, H. (2014). The new extractivism: A post-neoliberal development model or imperialism of the twenty-first century? Londres: Zed Books.

Postero, N. (2007). Now we are citizens: Indigenous politics in postmulticultural Bolivia. Redwood City, CA: Stanford University Press.

Prieto, M. (2016). Transando el agua, produciendo territorios e identidades indígenas: el modelo de aguas chileno y los atacameńos de Calama. Revista de Estudios Sociales (55), 88-103. http://dx.doi.org/10.7440/res55.2016.06

Prieto, M. (2017). El riego que el mercado no quiere ver: historia del despojo hídrico en las comunidades de Lasana y Chiu-Chiu (Desierto de Atacama, Chile). Journal of Latin American Geography, 16(2), 69-91. https://doi.org/10.1353/lag.2017.0022

Prudham, S. (2009). Commodification. En N. Castree, D. Demeritt, D. Liverman \& B. Rhoads (eds.), A companion to environmental geography (pp. 123-142). Oxford, uK: Wiley-Blackwell.

Prudham, W. S. (2005). Knock on wood: Nature as commodity in Douglas fir country. Nueva York: Routledge.

Rebolledo, L. (2012). Resistenciay cambios identitarios en trabajadores/as del salmón en Quellón. Polis, 11(31), 223-239. http://dx.doi.org/10.4067/S0718-65682012000100013

Rehner, J. (2012). Territorios corporativos: Una reflexión desde la geografía económica para evitar la axiomatización de los discursos. Revista de Geografía Espacios, 2(4), 27-47. http://www.revistaespacios.cl/?p=3607

Rehner, J., Baeza, S. A. \& Barton, J. R. (2014). Chile's resource-based export boom and its outcomes: Regional specialization, export stability and economic growth. Geoforum, 56, 35-45. http://dx.doi.org/10.1016/j.geoforum.2014.06.007

Robertson, M. (2000). No net loss: Wetland restoration and the incomplete capitalization of nature. Antipode, 32(4), 463-493. https://doi.org/10.1111/1467-8330.00146

Servicio Nacional de Geología y Minería (Sernageomin). (2011). Atlas de faenas mineras. Regiones de Antofagasta y Atacama. Mapas y Estadísticas de Faenas Mineras de Chile No. 7 (Versión actualizada). Santiago: Sernageomin. https://bit.ly/2A9Amo1

Servicio Nacional de Geología y Minería (Sernageomin) (2016). Anuario de la minería de Chile 2015. Santiago: Sernageomin. https://bit.ly/2LjpB6N

Smith, N. (1984). Uneven development: Nature, capital and the production of space: Oxford, UK: Blackwell.

Svampa, M. (2013). Resource extractivism and alternatives: Latin American perspectives on development. En D. Mokrani \& M. Lang (eds.), Beyond development: Alternative visions form Latin America (pp. 117-144). Quito: Rosa Luxemburg Foundation. https://bit.ly/2L3oyII

Vera-Bahamonde, H. (2010). La crisis del salmón ¿Por qué falló el tercer motor de la economía chilena? Santiago: Ril editores.

Watts, M. (2004). Resource curse? Governmentality, oil and power in the Niger Delta, Nigeria. Geopolitics, 9(1), 50-80. http://dx.doi.org/10.1080/14650040412331307832

Yáñez, N. \& Molina, R. (2011). Las aguas indígenas en Chile. Santiago: LOM Ediciones. 